\title{
Natalizumab-induced pneumonitis
}

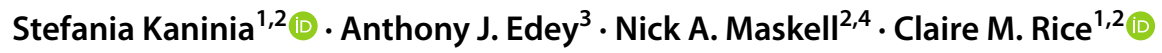

Received: 14 June 2021 / Revised: 17 September 2021 / Accepted: 18 September 2021 / Published online: 22 September 2021

(c) Springer-Verlag GmbH Germany, part of Springer Nature 2021

Dear Sirs,

Natalizumab is an anti- $\alpha 4$ integrin humanised monoclonal antibody approved for treatment of multiple sclerosis (MS) and Crohn's disease. Recognised treatment complications include infusion reactions and progressive multifocal leukoencephalopathy. We report pneumonitis associated with peripheral blood eosinophilia attributable to Natalizumab in a patient with co-existent MS and Crohn's disease.

A 39-year-old man presented with worsening dyspnoea and cough. Symptoms had been intermittent over several months and had not improved with antibiotics. There was a history of relapsing-remitting MS, Crohn's disease with short gut syndrome, and a chronic perianal abscess and pancreatitis. Monthly Natalizumab infusions had been commenced 6 months prior to presentation (Fig. 1). Additional medications included vitamin $\mathrm{D}$, folate, and multivitamins. He smoked and had no history of drug allergy. On examination, there was scattered expiratory wheeze on auscultation and $\mathrm{O}_{2}$ saturations on air were $80 \%$, rising to $>98 \%$ with $5 \mathrm{~L}$ $\mathrm{O}_{2}$. Inflammatory markers were elevated (C-reactive protein $115 \mathrm{mg} / \mathrm{L}$ and plasma viscosity $1.97 \mathrm{mPa} / \mathrm{s})$. There was a raised white cell count $\left(21.55 \times 10^{9} / \mathrm{L}\right)$ with neutrophilia

Claire M. Rice

c.m.rice@bristol.ac.uk

Stefania Kaninia

s.kaninia@nhs.net

Anthony J. Edey

anthony.edey@nbt.nhs.uk

Nick A. Maskell

nick.maskell@bristol.ac.uk

1 Department of Neurology, North Bristol NHS Trust, Bristol, UK

2 Bristol Medical School, University of Bristol, Bristol, UK

3 Department of Radiology, North Bristol NHS Trust, Bristol, UK

4 Department of Respiratory Medicine, North Bristol NHS Trust, Bristol, UK $\left(15.09 \times 10^{9} / \mathrm{L}\right)$ and eosinophilia $\left(2.87 \times 10^{9} / \mathrm{L}\right)$. Alkaline phosphatase was elevated (200 U/L) and the D-dimer was positive. Total immunoglobulin $\mathrm{E}$ was normal, but there was a newly identified, low concentration lambda monoclonal paraprotein. Normal or negative investigations included urea and electrolytes, ferritin, anti-nuclear and anti-neutrophil cytoplasm antibodies, as well as screening for severe acute respiratory syndrome coronavirus-2 (SARS-CoV-19). Vitamin D level in the peri-admission period was normal. A CT pulmonary angiogram demonstrated extensive broncho-centric and peripheral ground glass opacification with superimposed interlobular septal thickening consistent with interstitial lung disease but no evidence of acute or chronic thromboembolic disease (Fig. 2). Bronchoalveolar lavage fluid was clear and contained bronchial epithelial cells and alveolar macrophages; semiquantitative assessment of the cell count demonstrated $80 \%$ macrophages, $15 \%$ neutrophils, and 5\% lymphocytes. No significant organisms were identified on culture including prolonged culture for mycobacteria. A diagnosis of Natalizumab-induced pneumonitis was made; the drug was withdrawn and Prednisolone $30 \mathrm{mg}$ was commenced. Follow-up CT chest performed at 2 months and

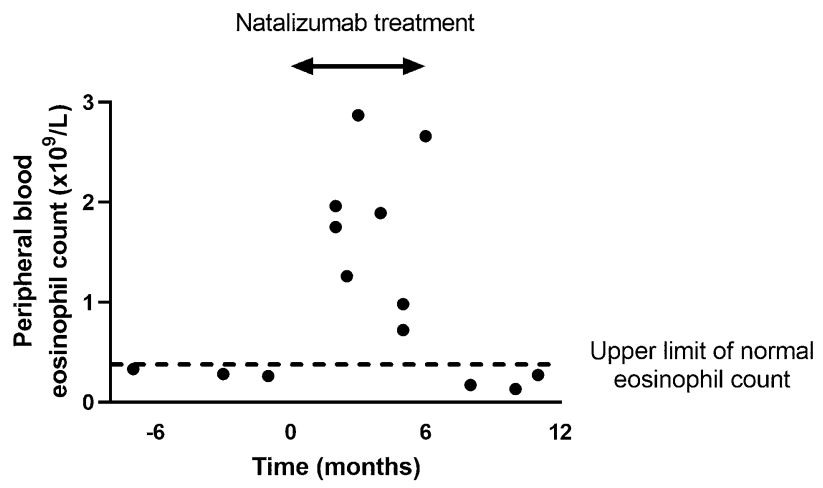

Fig. 1 Peripheral blood eosinophil count. Baseline eosinophil counts were normal but increased after introduction of Natalizumab. Following presentation with pneumonitis at 6 months, Natalizumab was withdrawn, and eosinophilia resolved 
Fig. 2 CT chest imaging. CT of the thorax at presentation (A) demonstrated extensive broncho-centric and peripheral ground glass opacification with superimposed interlobular septal thickening. Changes had resolved 2 months following discontinuation of Natalizumab (B)

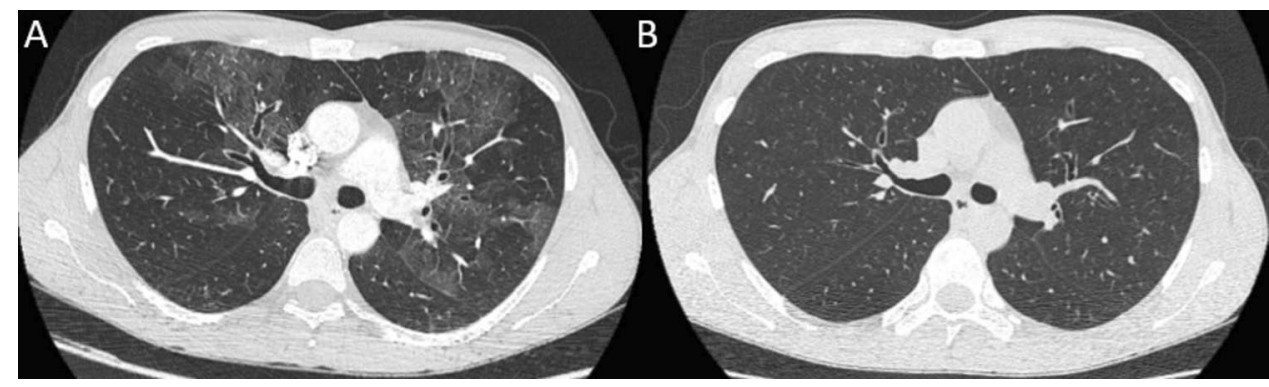

demonstrated almost complete resolution of abnormalities (Fig. 2), and, over a further 10 months, symptoms have not recurred despite corticosteroid wean.

Peripheral blood eosinophilia is a recognised side effect of Natalizumab therapy and has been reported to occur in $38 \%$ patients [1]. It is rarely symptomatic, but, when symptoms do occur, these tend to occur in the first 12 months of treatment. There are only three additional reported cases of pulmonary disease in the context of eosinophilia attributed to Natalizumab [1-3], although one case was also associated with positive PR3 ANCA serology [2]. Cases of dermatitis [4] and fasciitis [5] have also been reported.

Drug-induced interstitial lung disease is recognised following exposure to numerous medications including Alemtuzumab, another MS disease modifying therapy [6-8]. However, cases may only emerge after marketing authorisation [9]. The diagnosis is based, as in our case, on clinical, physiological and radiological findings in the context of an appropriate temporal relationship between symptoms and drug exposure and the absence of another more likely cause. Smoking and male sex have been identified as risk factors and prior exposure to immunomodulating drugs and genetic susceptibility may also be relevant [9]. The evidence basis for treatment is poor, although glucocorticoids are used widely. Identification and withdrawal of the offending agents are important to prevent irreversible complications including fibrosis.

The mechanism(s) of action underlying drug-induced eosinophilic pneumonitis remain unclear and may vary depending on the precipitant $[10,11]$. Eosinophil accumulation on vascular endothelial cells is thought to occur via interleukin (IL)-4 and IL-13 promotion of vascular cell adhesion molecule (VCAM)-1 expression. IL-5 primes eosinophils and enhances their survival. Chemokine-mediated transmigration across the vessel wall is mediated via the interactions of $\mathrm{cc}$ chemokine ligands and their receptors, particularly cc chemokine receptor (CCR) 3 and CCR5. Within lung tissue, a range of factors have been associated with eosinophil accumulation and activation including leukotriene B4, IL-33, and periostin [10].

This case highlights the importance of ongoing reporting of low frequency but potentially serious side effects in the post-marketing, surveillance phase of drug development. We recommend careful attention to the peripheral blood eosinophil count in those on treatment with Natalizumab, particularly when it exceeds $2 \times 10^{9} / \mathrm{L}$ in the first year of treatment [1]. As with Natalizumab-induced hypersensitivity reactions, clarification of the underlying genetic susceptibility factors may permit identification of those at greater risk of symptomatic eosinophilia with the potential to improve drug safety [12].

Acknowledgements We are grateful to the patient for permission to publish the case report. SK is supported by a fellowship from the European Committee for Treatment and Research in Multiple Sclerosis (ECTRIMS).

Funding No targeted funding reported. SK is supported by a fellowship from the European Committee for Treatment and Research in Multiple Sclerosis (ECTRIMS).

Availability of data and materials Not applicable.

Code availability Not applicable.

\section{Declarations}

Conflicts of interest The authors report no disclosures relevant to the manuscript.

Ethics approval Not applicable.

Consent to participate Not applicable.

Consent for publication Written consent for publication has been obtained from the patient. 


\section{References}

1. Diem L, Hoepner R, Bagnoud M et al (2021) Natalizumab induced blood eosinophilia: a retrospective pharmacovigilance cohort study and review of the literature. J Neuroimmunol 353:577505. https://doi.org/10.1016/j.jneuroim.2021.577505

2. Yasuda Y, Nagano T, Tachihara M et al (2019) Eosinophilic pneumonia associated with natalizumab in a patient with multiple sclerosis: a case report and literature review. Ther Clin Risk Manage 15:1283-1289. https://doi.org/10.2147/TCRM.S225832

3. Curto E, Munteis-Olivas E, Balcells E, Domínguez-Álvarez MM (2016) Pulmonary eosinophilia associated to treatment with natalizumab. Ann Thorac Med 11:224-226. https://doi.org/10.4103/ 1817-1737.185762

4. Andre M, Pacheco D, Antunes J et al (2010) Generalized skin drug eruption to natalizumab in a patient with multiple sclerosis. Derm Online J 16:14

5. Bujold J, Boivin C, Amin M et al (2014) Eosinophilic fasciitis occurring under treatment with natalizumab for multiple sclerosis. J Cutan Med Surg 18:69-71. https://doi.org/10.2310/7750.2013. 13026

6. Willis M, Cossburn M, Ingram G, et al (2015) Hypersensitivity pneumonitis following alemtuzumab treatment for multiple sclerosis. J Neurol Neurosurg Psychiatry 86:e4.31-e4. https://doi. org/10.1136/jnnp-2015-312379.126

7. Bianco A, Mari P-V, Larici AR et al (2020) Alemtuzumab-induced lung injury in multiple sclerosis: learning from adversity in three patients. Mult Scler Relat Disord 37:101450. https://doi.org/10. 1016/j.msard.2019.101450

8. Whiteside D, Barth S, Datta A, Trip SA (2018) Pneumonitis secondary to alemtuzumab in a patient with multiple sclerosis-a non-infectious cause of breathlessness. Mult Scler Relat Disord 22:139-140. https://doi.org/10.1016/j.msard.2018.04.002

9. Skeoch S, Weatherley N, Swift A et al (2018) Drug-induced interstitial lung disease: a systematic review. J Clin Med 7:356. https:// doi.org/10.3390/jcm7100356

10. Nakagome K, Nagata M (2020) Possible mechanisms of eosinophil accumulation in eosinophilic pneumonia. Biomolecules 10:638. https://doi.org/10.3390/biom10040638

11. Bartal C, Sagy I, Barski L (2018) Drug-induced eosinophilic pneumonia a review of 196 case reports. Medicine 97:e9688. https://doi.org/10.1097/MD.0000000000009688

12. Stüve $\mathrm{O}$, Hemmer B (2014) The genetics of natalizumab hypersensitivity: one learns to itch where one can scratch. Neurol Neuroimmunol NeuroInflammation 1:1-4. https://doi.org/10.1212/NXI. 0000000000000052 